\title{
Comparison of three malignancy risk indices and CA-125 in the preoperative evaluation of patients with pelvic masses
}

\author{
Zinatossadat Bouzari ${ }^{1,2 \dagger}$, Shahla Yazdani ${ }^{3^{*}{ }^{+}}$, Mahmoud Haji Ahmadi ${ }^{4 \dagger}$, Shahnaz Barat ${ }^{5 \dagger}$, Ziba Shirkhani Kelagar ${ }^{6 \dagger}$, \\ Maryam Javadian Kutenaie ${ }^{7 \dagger}$, Nargeuss Abbaszade ${ }^{8 \dagger}$ and Fateme Khajat ${ }^{8 \dagger}$
}

\begin{abstract}
Background: Patients with pelvic mass are the most referred patients to gynecologist. The aim of this study was to evaluate the ability of three malignancy risk indices (RMI 1, RMI 2 and RMI 3) and CA-125 to discriminate a benign from a malignant pelvic mass in our region (North of Iran).

Methods: This retrospective study was performed on 182 women with pelvic masses referred to Yahyanejad Hospital from 2007 to 2009. Ultrasound scans were scored as one point for each of the following characteristics: multilocular cyst, solid areas, intra-abdominal metastases, ascites, and bilateral lesions. For each patient a total ultrasound score $(U)$ was calculated. The difference of the three RMI was based on the allocation of the $U$ and $M$ scores. The sensitivity, specificity, positive predictive values (PPV) and negative predictive values (NPV) of level of serum CA-125, the RMI 1, 2 and 3 were compared.
\end{abstract}

Results: Mean age of the patients was $39.9 \pm 9.3$ years. Most of them were premenopausal (161 women or 88.4\%). A significant linear trend for malignancy was found by increasing age, ultrasound score, and serum CA-125. The best performance of CA125 was at a cut-off $88 \mathrm{U} / \mathrm{ml}$, with a sensitivity of $88 \%$, a specificity of $97 \%$, a positive predictive value of $84 \%$, and a negative predictive value of 99\%. RMI 1 and 3 at the optimal cut off point of 265 and RMI2 at the optimal cut off point of 355 , had a sensitivity of $91 \%$, specificity of $96 \%$, a positive predictive value of $78 \%$, and a negative predictive value of $99 \%$.

Conclusion: In our population we found that there is no statistically significant difference in the performance of three malignancy risk indices (RMI 1, RMI 2, and RMI 3) and CA125 in differentiating between benign and malignant pelvic masses.

\section{Background}

Patients with pelvic mass are the most referred patients to gynecologist. [1]. Ovarian cancer is one of the pelvic masses, the second most common gynecologic malignancy, the fifth cause of death due to cancers, and has more mortality than the other gynecologist malignancies $[2,3]$. Most cases are diagnosed at high stage where prognosis is very poor $[4,5]$. Regarding differentiation of benign versus malignant pelvic masses before surgery was difficult, therefore, Jacob et al. developed a Risk of

\footnotetext{
* Correspondence: shahla_yazdani_1348@yahoo.com

† Contributed equally

${ }^{3}$ Assistant professor, Department of OB\&GYN, Babol University of Medical

Sciences, Babol, Iran

Full list of author information is available at the end of the article
}

Malignancy Index (RMI) based on serum level of CA125, menopausal state and ultra sound findings[6]. The RMI has been adjusted by Tingulstad et al. [7] in 1996 (RMI2) and again modified in 1999 (RMI3) [8]. The RMI is a suitable index for evaluation of pelvic mass before surgeries and confirms previous studies indicating that RMI improves the discrimination between non malignant and malignant pelvic masses[5,9].

In many studies, cut off value of 200 for RMI 1 is the best discrimination for benign and malignant pelvic masses because of its high sensitivity and specificity levels[5]. The aim of this study was to evaluate the ability of three malignancy risk indices (RMI 1, RMI 2 and

\section{Biomed Central}

(c) 2011 Yazdani et al; licensee BioMed Central Ltd. This is an open access article distributed under the terms of the Creative Commons Attribution License (http://creativecommons.org/licenses/by/2.0), which permits unrestricted use, distribution, and reproduction in any medium, provided the original work is properly cited. 
RMI 3) and CA-125 to discriminate a benign from a malignant pelvic mass in our region.(North of Iran)

\section{Methods}

This retrospective study included the records of 182 consecutive women with pelvic masses, who were admitted for laparotomy between 2007 and 2009, at Yahyanejad Gynaecological Unit after signing a consent form approved by the Research Ethics Committee of Babol Medical University. Preoperative serum levels of CA-125 were measured by ELISA (Germany Roche Kit in the same laboratory), an ultrasonographic evaluation of their pelvic mass using a 2-7 MHZ abdominal transducer (General Electric, America) and a 12 MHZ transvaginal probe. Postmenopausal status was defined as more than 1 year of amenorrhea or an age of more than 50 years in women who have had a hysterectomy. Then RMI 1, 2, and3 were calculated for each patient. In all patients underwent the laparotomy, the histological specimens were sent to the pathology laboratory for the histopathologic diagnosis.

\section{Calculation of RMI}

Ultrasound scans were scored as one point for each of the following characteristics: multilocular cyst, solid areas, intra-abdominal metastases, ascites, and bilateral lesions. For each patient a total ultrasound score (U) was calculated. The difference of the three RMI is based on the allocation of the $\mathrm{U}$ and $\mathrm{M}$ scores.

RMI $1=\mathrm{U} \times \mathrm{M} \times \mathrm{CA} 125$; an ultrasound score of 0 considered as $U=0$, a score of 1 considered as $U=1$, and a score of ? 2 considered as $U=3$. Premenopausal status considered as $M=1$ and postmenopausal status considered as $M=3$. The serum level of CA125 was used directly in the calculation[6].

RMI $2=\mathrm{U} \times \mathrm{M} \times \mathrm{CA} 125$; an ultrasound score of 0 or 1 considered as $U=1$, and a score of $i 2$ considered as $\mathrm{U}=4$. Premenopausal status considered as $\mathrm{M}=1$ and postmenopausal status considered as $M=4$. The serum level of CA125 was used directly in the calculation[7].

RMI $3=\mathrm{U} \times \mathrm{M} \times \mathrm{CA} 125$; an ultrasound score of 0 or 1 considered as $U=1$, and a score of $i 2$ considered as $\mathrm{U}=3$. Premenopausal status considered as $\mathrm{M}=1$ and postmenopausal status considered as $M=3$. The serum CA125 level was used directly in the calculation[8].

\section{Statistical analysis}

All data was analysed by SPSS18. We used the T-Test, Pearson Chi-square and Mann-Whitney U. Receiver Operating Characteristics (ROC) Curve was plotted and the sensitivity, specificity, positive(PPV) and negative predictive values(NPV) were determined. The McNemar's test was used when testing differences in performances between RMI 1, RMI 2 and RMI 3. A probability value of $\mathrm{P}<0.05$ was considered to be statistically significant.

\section{Results}

Mean age of the patients was $39.9 \pm 9.3$ years. Most of them were premenopausal (161 women or $88.4 \%$ ). The distribution of age, menopausal status, ultrasound score (U) and serum CA-125 level in women with benign and malignant pelvic mass were described in Table 1. In univariate analysis, a significant linear trend for malignancy was found by increasing age, ultrasound score, and serum CA-125. Table 2 lists the histology results, indicating that 158(87.3\%), 23(12.7\%) and $1(0.5 \%)$ were benign, malignant and tuberculosis masses, respectively.

The performance of RMI 1, RMI 2, RMI 3, and CA125 at different cutoff levels are presented in Table 3. A direct comparison of the three RMI indices showed that there were not any significant difference between RMI1 and 3 at a cutoff level of 265 and RMI2 at a cutoff level of 355 ( $\mathrm{p}>0.05$ ). The performance of RMI 1, RMI 2, RMI 3 and CA125 are presented in receiver operator characteristic curves (Figure 1). The detail of false positive and false negative cases based on the cut-off level criteria of RMI 1, 2, 3 and CA125 according to their histology are shown in Table 4.

\section{Discussion}

Our study showed the usefulness of the CA125 in prereferral evaluation of patients with demonstrated pelvic masses. We were determined that the different serum level of CA 125 in benign and malignant pelvic mass is similar to other studies $[1,10]$. The best performance of CA125 in our study was at a cut-off $88 \mathrm{U} / \mathrm{ml}$, with a sensitivity of $88 \%$, a specificity of $97 \%$, a positive predictive value of $84 \%$, and a negative predictive value of

Table 1 The distribution of age, menopausal status, ultrasound score (U), serum CA 125 level in women with benign and malignant pelvic masses

\begin{tabular}{lccc}
\hline Parameter & $\begin{array}{c}\text { Benign } \\
(\mathbf{n}=\mathbf{1 5 8})\end{array}$ & $\begin{array}{c}\text { malignant } \\
(\mathbf{n}=\mathbf{2 3})\end{array}$ & P-value \\
\hline Age (mean) & $38.7 \pm 8.3$ & $47.7 \pm 12.5$ & $0.003^{*}$ \\
menopausal status (M) & $145(91.8 \%)$ & $16(69.9 \%)$ & $0.002^{*}$ \\
Premenopausal & $13(8.2 \%)$ & $7(30.4 \%)$ & \\
Post menopausal & & & \\
Ultrasound score (U) & $45(28.5 \%)$ & $0(0 \%)$ & $0.001^{*}$ \\
$U=0$ & $50(31.6 \%)$ & $0(0 \%)$ & \\
$U=1$ & $63(39.9 \%)$ & $23(100 \%)$ & \\
$U=2-5$ & 21 & 112 & $<0.001^{*}$ \\
SerumCA-125(median)(U/ml) & & & \\
*P $<0.05$ & &
\end{tabular}


Table 2 Definitive histopathological diagnosis of adnexal masses

\begin{tabular}{lll}
\hline Diagnosis & $\mathbf{n}$ & $\%$ \\
\hline Ovarian cancer & & \\
Stage I & 8 & 4.3 \\
Stage II & 1 & 0.5 \\
Stage III & 11 & 6.0 \\
Stage IV & 3 & 1.6 \\
Total malignant tumors & 23 & 12.6 \\
Metastatic tumor & 2 & 1.1 \\
Granulosa cells tumor & 2 & 1.1 \\
Serous papillary adenocarcinoma & 9 & 4.9 \\
dysgerminoma & 1 & 0.5 \\
Clear cell adenocarcinoma & 1 & 0.5 \\
Serous cystadenoma & 1 & 0.5 \\
Endometrioma & 37 & 20.3 \\
Dermoid cyst & 29 & 15.9 \\
hemorrhagic cyst & 10 & 5.5 \\
Paratubal cyst & 21 & 11.5 \\
Follicular simple cyst & 10 & 5.5 \\
Leiomyoma & 10 & 5.5 \\
Corpus luteum cyst & 18 & 9.9 \\
inclusion cyst & 2 & 1.1 \\
Borderline Tumors & & \\
Mucinous adenocarcinoma & 6 & 3.2 \\
Serous adenocarcinoma & 2 & 1.1 \\
Infective conditions & & \\
Tuberculosis mass & & 0.5 \\
\hline
\end{tabular}

99\%. Although, this good performance might lie on the distribution of tumor histology, which we showed in table 2.

The results of previous studies describe that many studies showed the best cut off point for RMI is 200 $[1,5-8,11]$. However in this study, RMI 1 and 3 at the optimal cut off point of 265 and RMI 2 at the optimal cut off point of 355 , had a sensitivity of $91 \%$, specificity of $96 \%$, a positive predictive value of $78 \%$, and a negative predictive value of $99 \%$. Bailey et al. study on 182 women with pelvic masses indicated an RMI $>200$ had a sensitivity of $88.5 \%$ for diagnosing invasive lesions[12]

Table 3 Sensitivity, specificity, positive, negative predictive values of three RMI and CA125

\begin{tabular}{cllll}
\hline Methods & $\begin{array}{l}\text { Sensitivity } \\
\text { (\%) }\end{array}$ & $\begin{array}{l}\text { Specificity } \\
\text { (\%) }\end{array}$ & $\begin{array}{l}\text { PPV } \\
\text { (\%) }\end{array}$ & $\begin{array}{l}\text { NPV } \\
\text { (\%) }\end{array}$ \\
\hline RMI 1\&3 (cutoff: 200) & 91 & 88 & 53 & 99 \\
RMI 2 (cutoff: 200) & 91 & 79 & 39 & 98 \\
RMI 1\&3 (cutoff: 265) & 91 & 96 & 78 & 99 \\
RMI 2 (cutoff: 355) & 91 & 96 & 78 & 99 \\
CA-125 (cut-off: 88 U/ & 87 & 97 & 84 & 99 \\
mL) & & & & \\
\hline
\end{tabular}

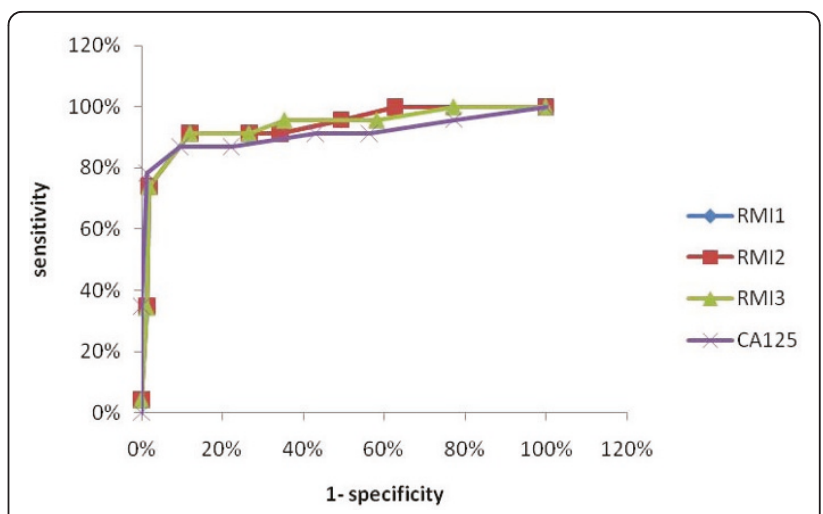

Figure 1 ROC curve showing the relationship between specificity and sensitivity for RMI 1, RMI 2, RMI 3 and CA125 in differentiating between benign and malignant pelvic masses.

while Engelen et al. study on 302 women with pelvic mass indicated an RMI at a cut off point of 250 had a sensitivity of $88.2 \%$, a specificity of $74.3 \%$, a PPV of $71.3 \%$, a NPV of $90 \%$ for diagnosing invasive lesions[13].

A systematic review study by Geomini P et al. in 2009, 116 diagnostic studies for adnexal malignancy was reviewed. The reported result showed that at the cut off point of 200 , RMI has a sensitivity of $78 \%$ and specificity $87 \%$ for malignant mass diagnoses[14] which is similar to our report.

When RMIs cutoff was set at 265 or 355 and CA125 at $88 \mathrm{U} / \mathrm{ml}$, all borderline tumors (mucinous adenocarcinoma and serous adenocarcinoma) and all stage I, were correctly identified prior to surgery, this increased the sensivity but not at the expense of increasing the false positive rate. Thus these cut offs are very useful at the peripheral hospitals and health centers to accelerate prompt referral of positive cases to tertiary hospitals. We showed that CA-125 at the cut-off $88 \mathrm{U} / \mathrm{ml}$ performed as well as the RMI 1 and 3 at a cut-off 265 and RMI 3 at a cut-off 355 in differentiating between benign and malignant pelvic masses.

Table 4 False-positive cases and false-negative cases of three malignancy risk indices RMI 1, 2, 3 and CA125

\begin{tabular}{ccccc}
\hline & $\begin{array}{c}\text { RMI 1 } \\
\text { (cutoff: } \\
\text { 265) }\end{array}$ & $\begin{array}{c}\text { RMI 2 } \\
\text { (cutoff: } \\
\text { 355) }\end{array}$ & $\begin{array}{c}\text { RMI 3 } \\
\text { (cutoff: } \\
\text { 265) }\end{array}$ & $\begin{array}{c}\text { CA125 } \\
\text { (cut off: } \\
\text { 88) }\end{array}$ \\
\hline False-positive cases & & & & \\
endometriosis & 5 & 5 & 5 & 3 \\
$\begin{array}{c}\text { Mucinous } \\
\text { cystadenoma }\end{array}$ & 1 & 1 & 1 & 1 \\
$\begin{array}{c}\text { False-negative cases } \\
\text { granulosa cell }\end{array}$ & 1 & 1 & 1 & 1 \\
tumor & & & & \\
\hline
\end{tabular}




\section{Conclusion}

In our population we found that there is no statistically significant difference in the performance of three malignancy risk indices (RMI 1, RMI 2, and RMI 3) and CA125 in differentiating between benign and malignant pelvic masses.

\section{Acknowledgements}

We would like to thank the Vice Chancellor for Research and technology, Babol University of Medical Sciences.

\section{Author details}

${ }^{1}$ Assistant professor, Department of OB\&GYN of Babol University of Medical Sciences, Babol, Iran. ${ }^{2}$ Member of stem cell researcher center of Babol University of Medical Sciences, Babol, Iran. ${ }^{3}$ Assistant professor, Department of OB\&GYN, Babol University of Medical Sciences, Babol, Iran. ${ }^{4}$ Statistician, Babol University of Medical Sciences, Babol, Iran. ${ }^{5}$ Assistant professor, Department of OB\&GYN, Babol University of Medical Sciences, Babol, Iran. ${ }^{6}$ Statistician, Babol University of Medical Sciences, Babol, Iran. ${ }^{7}$ Medical student of Babol University of Medical Sciences, Babol, Iran. ${ }^{8}$ B\&GYN, Babol University of Medical Sciences, Babol, Iran.

\section{Authors' contributions}

Each author has participated actively and sufficiently in this study. ZB conceived the idea and design of the study, interpretation of data, and drafted the manuscript. SHY conceived the idea and design of the study. $\mathrm{MHJ}$ and $\mathrm{ZSH}$ made substantial contribution to analysis and interpretation of data. SHB, MJK, NA, and FKH have made contribution to collecting of data and editing. Each author revised critically the manuscript and provided final approval of the version to be published.

\section{Competing interests}

The authors declare that they have no competing interests.

Received: 25 January 2011 Accepted: 20 June 2011

Published: 20 June 2011

\section{References}

1. Obeidat B, Amarin Z, Latimer J, Crawford R: Risk of malignancy index in the preoperative evaluation of pelvic masses. International Journal of Gynecology \& Obstetrics 2004, 85(3):255-8.

2. Greenlee R, Hill Harmon M, Murray T, Thun M: Cancer statistics, 2001. CA: a cancer journal for clinicians 2001, 51(1):15-36.

3. Landis S, Murray T, Bolden S, Wingo PA: Cancer statistics. Cancer J Clin 1998, 48:6-29

4. Goldstein S: Postmenopausal adnexal cysts: how clinical management has evolved. American Journal of Obstetrics and Gynecology 1996, 175(6):1498-501.

5. van den Akker P, Aalders A, Snijders M, Kluivers K, Samlal R, Vollebergh J, et al: Evaluation of the risk of malignancy index in daily clinical management of adnexal masses. Gynecologic Oncology 2010, 116(3):384-8.

6. Jacobs I, Oram D, Fairbanks J, Turner J, Frost C, Grudzinskas J: A risk of malignancy index incorporating CA 125 , ultrasound and menopausal status for the accurate preoperative diagnosis of ovarian cancer. BJOG: An International Journal of Obstetrics \& Gynaecology 1990, 97(10):922-9.

7. Tingulstad S, Hagen B, Skjeldestad F, Onsrud M, Kiserud T, Halvorsen T, et al: Evaluation of a risk of malignancy index based on serum CA125, ultrasound findings and menopausal status in the pre operative diagnosis of pelvic masses. BJOG: An International Journal of Obstetrics \& Gynaecology 1996, 103(8):826-31.

8. Tingulstad S, Hagen B, Skjeldestad F, Halvorsen T, Nustad K, Onsrud M: The risk-of-malignancy index to evaluate potential ovarian cancers in local hospitals. Obstetrics \& Gynecology 1999, 93(3):448.

9. Akdeniz N, Kuyumcuoglu U, Kale A, Erdemoglu M, Caca F: Risk of malignancy index for adnexal masses. European journal of gynaecological oncology 2009, 30(2):178-80.

10. Yamamoto Y, Yamada R, Oguri H, Maeda N, Fukaya T: Comparison of four malignancy risk indices in the preoperative evaluation of patients with pelvic masses. European Journal of Obstetrics \& Gynecology and Reproductive Biology 2009, 144(2):163-7.

11. Ulusoy S, Akbayir O, Numanoglu C, Ulusoy N, Odabas E, Gulkilik A: The risk of malignancy index in discrimination of adnexal masses. International Journal of Gynecology \& Obstetrics 2007, 96(3):186-91.

12. Bailey J, Tailor A, Naik R, Lopes A, Godfrey K, Hatem H, et al: Risk of malignancy index for referral of ovarian cancer cases to a tertiary center: does it identify the correct cases? International Journal of Gynecological Cancer 2006, 16(S1):30-4.

13. Engelen MJA, Bongaerts AHH, Sluiter WJ, de Haan HH, Bogchelman DH, TenVergert EM, et al: Distinguishing benign and malignant pelvic masses: The value of different diagnostic methods in everyday clinical practice. European Journal of Obstetrics \& Gynecology and Reproductive Biology 2008, 136(1):94-101.

14. Geomini P, Kruitwagen R, Bremer G, Cnossen J, Mol B: The accuracy of risk scores in predicting ovarian malignancy: a systematic review. Obstetrics \& Gynecology 2009, $113(2$ Part 1):384.

doi:10.1186/1756-0500-4-206

Cite this article as: Bouzari et al:: Comparison of three malignancy risk indices and CA-125 in the preoperative evaluation of patients with pelvic masses. BMC Research Notes 2011 4:206.

\section{Submit your next manuscript to BioMed Central and take full advantage of:}

- Convenient online submission

- Thorough peer review

- No space constraints or color figure charges

- Immediate publication on acceptance

- Inclusion in PubMed, CAS, Scopus and Google Scholar

- Research which is freely available for redistribution

Submit your manuscript at www.biomedcentral.com/submit
C Biomed Central 